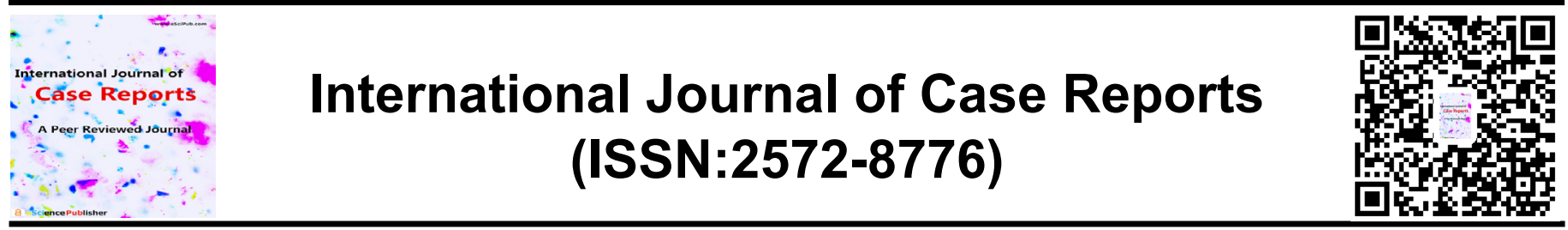

\title{
Intra Cholecystic Papillary Tubular Neoplasm - A Case Report Of A Rare Differential Diagnosis Of Carcinoma Gall Bladder
}

\section{Dr. Sana Aboosalih ${ }^{*}$, Dr. K. R. Manoj Prabu², Dr. P. Jayaganesh ${ }^{3}$, Dr. Pichaimuthu} Anbalagan $^{4}$, Dr. Devy Gounder Kannan ${ }^{5}$, Dr. Arcot Rekha ${ }^{6}$

${ }^{1}$ Surgical Resident, Dept. of General Surgery, Saveetha Medical College, Chennai, Tamil Nadu, India. ${ }^{2}$ Assistant Professor, Dept. of General Surgery, Saveetha Medical College, Chennai, Tamil Nadu, India. ${ }^{3}$ Assistant professor, Dept. of Pathology, Saveetha Medical College, Chennai, Tamil Nadu, India. ${ }^{4}$ Assistant Professor, Dept. of Surgical Gastroenterology, Saveetha Medical College, Chennai, Tamil Nadu, India. ${ }^{5}$ Professor and HOD, Dept. of Surgical Gastroenterology, Saveetha Medical College, Chennai, Tamil Nadu, India. ${ }^{6}$ Professor and Unit Cheif, Dept. of General Surgery, Saveetha Medical College, Chennai, Tamil Nadu, India

\section{ABSTRACT}

We present a case report of a 57year old lady who presented *Correspondence to Author: with complaints of right sided upper abdominal pain. The patient was initially diagnosed with carcinoma gall bladder(CAGB) by CECT Abdomen and PET CT imaging studies. Intra cholecystic papillary tubular neoplasm of the gall bladder(ICPN) was diagnosed after histopathological examination of the radical

cholecystectomy specimen. ICPN can be managed with a How to cite this article:

cholecystectomy if the diagnosis is known pre operatively as the prognosis for ICPN is much better as compared with that for gallbladder adenocarcinoma.

Dr. Sana Aboosalih

Surgical Resident, Dept. of General Surgery, Saveetha Medical College, Chennai, Tamil Nadu, India.

Sana Aboosalih, K. R. Manoj Prabu, P. Jayaganesh, Pichaimuth Anbalagan, Devy Gounder Kannan, Arcot Rekha. Intra Cholecystic Pap-

Keywords: Intra Cholecystic Papillary Tubular Neoplasm Gall illary Tubular Neoplasm- A Case bladder; Carcinoma Gall Bladder; Radical Cholecystectomy; Report Of A Rare Differential DiagCase Report nosis Of Carcinoma Gall Bladder. International Journal of Case Reports, 2020; 5:157.

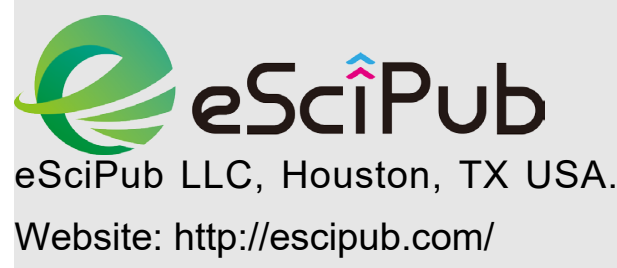




\section{Introduction}

Intraepithelial neoplasia is a preinvasive neoplastic lesions found throughout in the digestive system. Such lesions when found in the gallbladder, are referred as intra cholecystic papillary neoplasm (ICPN). ICPN are rare tumours which show intraluminal papillary growth that can be associated with invasive carcinoma. Their natural history remains poorly understood. ICPN rarely infiltrates and metastasizes, and hence has better outcomes.

\section{CASE REPORT}

57 years old lady presented to the surgery OPD at Saveetha Medical College, Chennai with complaints of pain in the upper abdomen (right hypochondrium and epigastric region) for the past three days associated with vomiting. The pain was colicky in nature and the pain radiated to the back. There was no significant weight loss and she had no loss of appetite. Ultrasound study revealed a $12 \times 6 \mathrm{~mm}$ echogenic focus adherent to the wall of the gall bladder suspicious of neoplastic growth with dilated CBD and IHBR. A CT abdomen study showed a fairly defined dense lobulated lesion measuring approximately $2.8 \times 1.1 \mathrm{~cm}$ in body of the gall bladder, which on contrast administration showed moderate enhancement in arterial and venous phase (Fig 1).

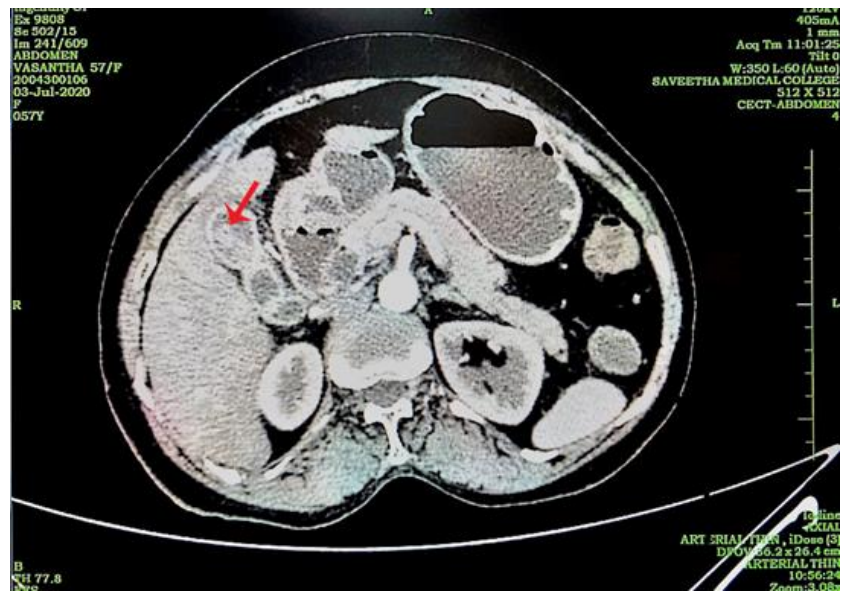

Fig1: Red arrow shows a fairly defined soft tissue dense lobulated lesion measuring $2.8 \times 1.1 \mathrm{~cm}$ in the body of the gall bladder.

UGI scopy was normal. Tumor markers CA19.9 was $27.1 \mathrm{U} / \mathrm{ml}$ and CEA $1.11 \mathrm{ng} / \mathrm{ml}$ (showed no significant elevation). Patient underwent a PET CT scan which showed hyper metabolic mass with SUV max of 8.7 in the gall bladder suggestive of carcinoma (Fig 2), the lesion being adherent to the gall bladder fossa of liver suggestive of early invasion, $8 \mathrm{~mm}$ calculus was also noted in the gall bladder.

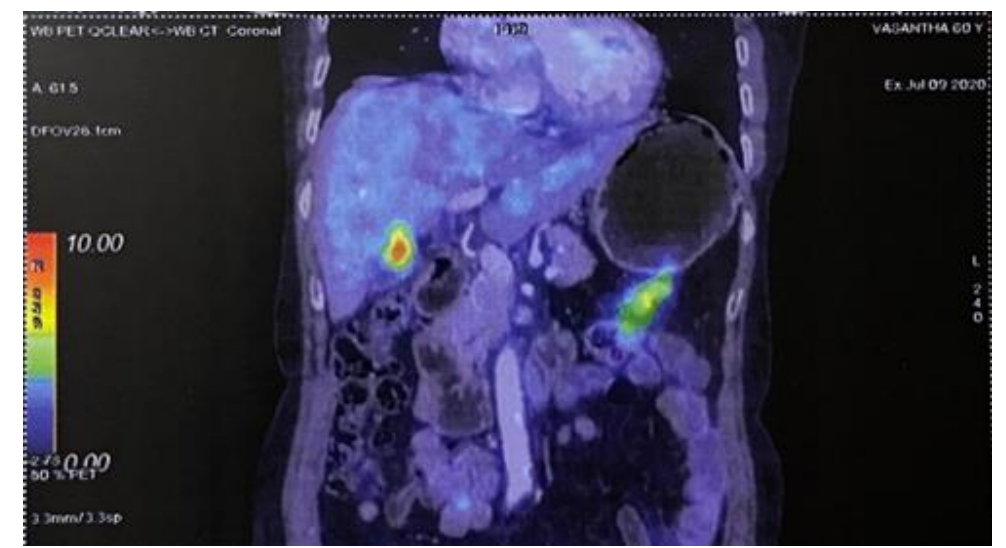

Fig 2: Hyper metabolic mass in the gall bladder suggestive of carcinoma on PET CT. SUV max 8.7. Iesion appears adherent to the gall bladder fossa of liver suggestive of an early invasion. 
Bulging ampulla was noted and there was no evidence of mass in the ampulla, periampullary region or pancreas. An $8 \mathrm{~mm}$ cyst was noted in segment $4 \mathrm{~b}$ of liver. Patient underwent a radical cholecystectomy procedure. The findings were a subhepatic appendix with pulled up caecum, liver and peritoneal surface free of metastasis and a pedunculated growth of size $1.8 \times 1.5 \mathrm{x}$ $1 \mathrm{~cm}$ in the post wall of the gall bladder with a $1 \mathrm{~cm}$ gall bladder calculi. Adjacent $5.5 \times 3.5 \mathrm{cms}$ of liver segment $4 \mathrm{~b}$ and $V$ was resected.
Histopathological examination of the specimen revealed a polypoidal structure with tubular and papillary structures. The tubules are lined by columnar epithelium with focal areas showing goblet cells and pyloric type mucosa. Focal areas showed mild nuclear enlargement depicting low grade dysplasia. No invasion was noted. The features were consistent with intra cholecystic papillary tubular neoplasm of the gall bladder (Fig 4).

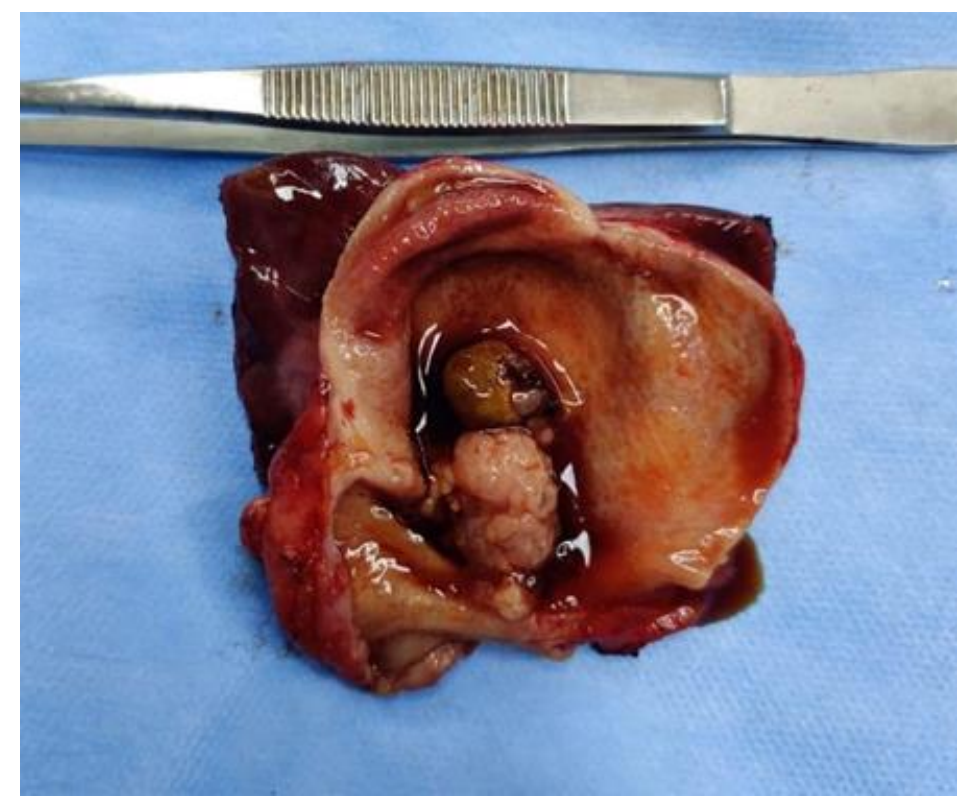

Fig 3: Gross specimen - pedunculated growth of size $1.8 \times 1.5 \times 1 \mathrm{~cm}$ in the post wall of the gall bladder with a $1 \mathrm{~cm}$ gall bladder calculi with the adjacent $5.5 \times 3.5 \mathrm{cms}$ of liver attached to the gall bladder.

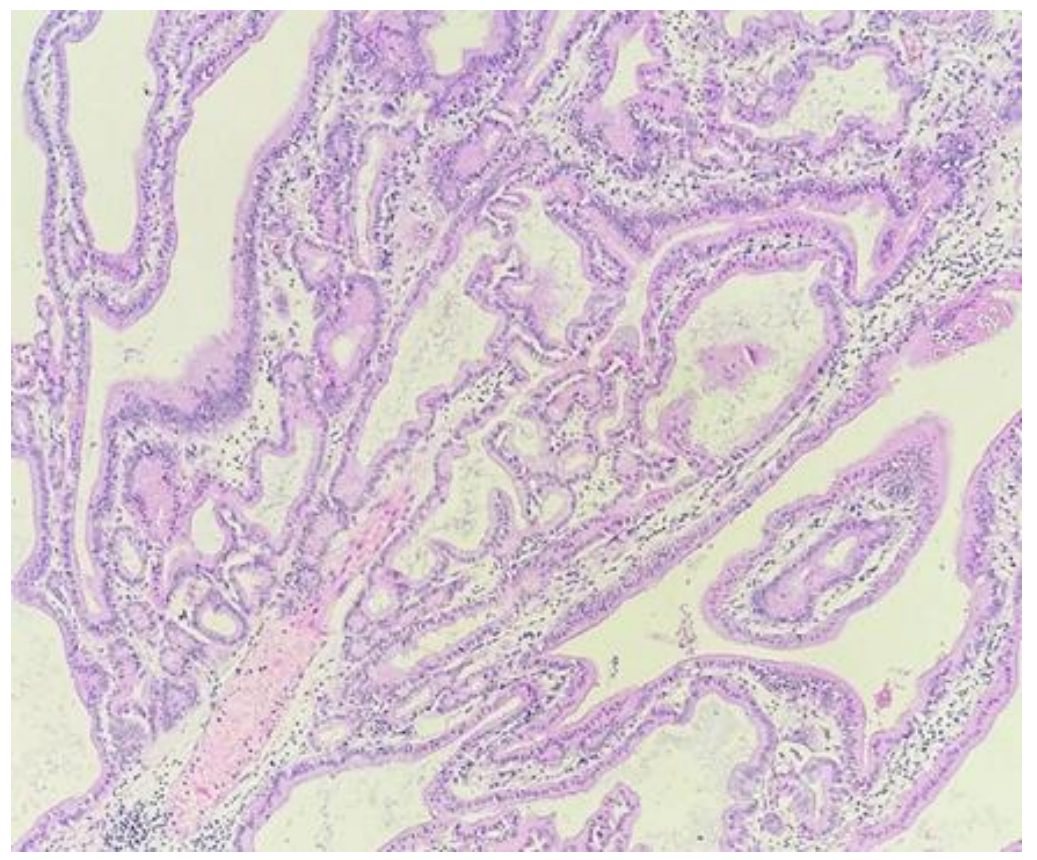

Fig 4: Microscopic features of ICPN - Tumor cells are arranged in a papillary architecture along thin fibro vascular stalks.

IJCR: https://escipub.com/international-journal-of-case-reports/ 


\section{Discussion}

Benign lesions of the gall bladder include inflammatory, cholesterol and adenomatous polyps, fibromas, leiomyomas, lipomas, hemangiomas, granular cell tumors, and heterotopic tissue, including gastric, pancreatic, and intestinal epithelium. Carcinoma of the gall bladder occurs in $50.0 \%$ of the gall bladders examined microscopically. Of these $90.0 \%$ are adenocarcinomas, $2 \%$ are squamous cell carcinomas and approximately $5 \%$ represent papillary adenocarcinomas. Intra cholecystic papillary-tubular neoplasm (ICPN) is a relatively new entity which includes neoplastic polyps, adenomas, and papillary neoplasms that are $\geq 1.0 \mathrm{~cm}$.

ICPN was first described as gallbladder lesions of IPNB in the 2010 WHO classification and was classified as premalignant lesions of biliary system in the same category as adenoma, biliary intraepithelial neoplasia, and mucinous cystic neoplasm. They are more common in women and in the age group 26-65 years. They follow an adenoma carcinoma progression and have 5 different lineages of differentiation. ICPN has a histological pattern from stomach to colon. Five different patterns such as biliary, gastric pyloric, gastric foveolar, intestinal, and oncocytic types are recognized till now. The ICPN has tubular and papillary elements, with the latter more likely to be invasive. High grade dysplasia is a precursor for invasive cancer.

A simple cholecystectomy is sufficient for the treatment of non invasive ICPN as it rarely infiltrates or metastasizes. The 5-year survival rate for ICPN is $60 \%$ if including invasive carcinoma and $78 \%$ if excluding the invasive region. In contrast, the 5-year survival rate for gallbladder adenocarcinoma is $30 \%$. However, it is difficult to preoperatively differentiate whether a growth in the Gall bladder is an ICPN or an adenocarcinoma.

Gallbladder polyps can be incidentally found on ultrasound or other imaging modalities. Preoperative imaging using CT or MRI is unable to differentiate ICPN from Carcinoma of gall bladder. The features described in view of ICPN are: ${ }^{11]}$ intramucosal, ${ }^{[2]}$ preinvasive neoplastic (dyspla- stic), ${ }^{33]}$ mass forming: exophytic (papillary or polypoid), ${ }^{[4]}$ size more than $1.0 \mathrm{~cm},{ }^{[5]}$ compact, and [6] distinct from the neighboring mucosa. However, ICPN is a novel concept, and the diagnostic features remain uncertain [27]. In a study by Sakamoto et al. a novel scoring system using CEA and tumor diameter is used to predict the tumor depth of CAGB. CEA values are important for preoperative evaluation of CAGB [28]. Many studies show an increase in CA19.9 in the later stages of CAGB, however both CEA and CA19.9 have low specificity (CA $19-9$ 92.7\% versus $79.20 \%$ CEA) and sensitivity (CA $19-950 \%$ vs $79.4 \%$ CEA) and baseline tests are only useful in monitoring response to therapy.

CAGB has a one-year mortality of $85 \%$ and a 5 years survival of $5 \%$. The poor prognosis is attributed to late presentations with advanced stage of disease. In the present day, there is no physical exam findings, blood test or imaging findings that is highly suggestive of gallbladder cancer, which can be used as an early detection screening process worldwide [29, 30].

PET CT is not routinely recommended for staging in CAGB, although it may be useful for detection of regional nodal metastases and distant metastatic disease. Generally, a high FDG-uptake is associated with CAGB and a lower uptake is seen in benign etiologies such as focal adenomyomatosis, chronic cholecystitis or xanthogranulomatous cholecystitis. High uptake in the polyp compared to liver parenchyma has high sensitivity and specificity for malignancy in polyps larger than $1 \mathrm{~cm}$. SUVmax is a semiquantitative tool for assessing metabolic uptake. This is highly dependent on BMI, age, sex and injected FDG activity [31]. In our case PET CT showed and SUV max of 8.7 which is high and hence lead to higher suspicion of malignancy. ICPNs account for only $6.5 \%$ of all surgically resected gallbladder neoplasms of which $16 \%$ are papillary tumors. Immunohistochemical studies of ICPN suggest that there is a higher expression of MUC5AC and MUC6, as compared to CAGB. ICPNs are genetically distinct from papillary and non-papillary gall bladder carcinomas. STK11, CTNNB1, and APC being identified as 
major contributory genes for ICPNs ${ }^{[32]}$.

\section{Conclusions}

ICPN account for $6.5 \%$ of resected gallbladder neoplasms. Given that they have a better prognosis as compared to adenocarcinoma, the surgeon must be aware of this pre invasive entity. While preoperative definitive diagnosis is difficult, frozen section can preclude a need for extensive radical dissection.

\section{References}

[1] Adsay V, Jang KT, Roa JC, Dursun N, Ohike N, Bagci $P$, et al. Intra cholecystic papillary-tubular neoplasms (ICPN) of the gallbladder (neoplastic polyps, adenomas, and papillary neoplasms that are $\geq 1.0 \mathrm{~cm}$ ): Clinicopathologic and immunohistochemical analysis of 123 cases. Am J Surg Pathol 2012;36:1279-301.

[2] Xiao SY. Intraductal papillary mucinous neoplasm of the pancreas: An update. Scientifica (Cairo) 2012;2012:893632.

[3] Xue-Shuai W, Yi-Yao X, Xin-Ting S. Intraductal papillary neoplasm of the bile duct. World $\mathrm{J}$ Gastroenterol 2013;19:8595-604

[4] Albores-Saavedra J, Tuck M, McLaren BK, Carrick KS, Henson DE. Papillary carcinomas of the gallbladder: Analysis of noninvasive and invasive types. Arch Pathol Lab Med 2005;129: 905-9.

[5] Isozaki M, Ohike N, Tajiri T, Mitsuya T, Takimoto M. Clinicopathological study of intra cholecystic papillary-tubular neoplasms (ICPNs) of the gallbladder. Showa Univ J Med Sci 2014;26:17-26.

[6] Bennett S, Marginean EC, Paquin-Gobeil M, Wasserman J, Weaver J, Mimeault R, et al. Clinical and pathological features of intraductal papillary neoplasm of the biliary tract and gallbladder. HPB (Oxford) 2015;17:811-8.

[7] Argon A, Barbet FY, Nart D. The relationship between intra cholecystic papillary-tubular neoplasms and invasive carcinoma of the gallbladder. Int J Surg Pathol 2016;24:504-11.

[8] Hashimoto S, Horaguchi J, Fujita N, Noda $Y$, Kobayashi G, Ito K, et al. Intra cholecystic papillary-tubular neoplasm of the gallbladder presenting with jaundice. Intern Med 2014;53:23 13-7

[9] Yamamoto K, Yamamoto F, Maeda A, Igimi $\mathrm{H}$, Yamamoto M, Yamaguchi R, et al. Tubulopapillary adenoma of the gallbladder accompanied by bile duct tumor thrombus. World J Gastroenterol 2014;20:8736-9.

[10] Serdar B, Gizem A, Carlos RJ, Volkan AN. Intracholecystic papillary tubular neoplasm of the gallbladder with microinvasive carcinoma. Pathol Case Rev 2014;19:283-8.

[11] Hamdani NH, Qadri SK, Aggarwalla R, Bhartia VK, Chaudhuri S, Debakshi S, et al. Clinicopathological study of gall bladder carcinoma with special reference to gallstones: Our 8-year experience from Eastern India. Asian Pac J Cancer Prev 2012;13:5613-7.

[12] Poudel R, Singh SK, Basnet S, Dev Kota H, Adhkari SK. Clinicopathological study of gall bladder cancer and its relationship with gall stones. J Soc Surg Nepal 2016;18:46.

[13] Unisa S, Jagannath P, Dhir V, Khandelwal C, Sarangi L, Roy TK, et al. Population-based study to estimate prevalence and determine risk factors of gallbladder diseases in the rural gangetic basin of North India. HPB (Oxford) 2011;13:117-25.

[14] Singh V, Trikha B, Nain C, Singh K, Bose S. Epidemiology of gallstone disease in Chandigarh: A community-based study. J Gastroenterol Hepatol 2001;16:560-3.

[15] Seretis C, Lagoudianakis E, Gemenetzis G, Seretis F, Pappas A, Gourgiotis S, et al. Metaplastic changes in chronic cholecystitis: Implications for early diagnosis and surgical intervention to prevent the gallbladder metaplasia-dysplasia-carcinoma sequence. J Clin Med Res 2014;6:26-9.

[16] Wan X, Zhang H, Chen C, Yang X, Wang A, Zhu $\mathrm{C}$, et al. Clinicopathological features of gallbladder papillary adenocarcinoma. Medicine (Baltimore) 2014;93: e131

[17] Recio-Boiles A, Kashyap S, Babiker HM. Cancer, Gallbladder. [Updated 2020 Apr 21]. In: StatPearls [Internet]. Treasure Island (FL): StatPearls Publishing; 2020 Jan.

[18] Bennett, S., Celia Marginean, E., Paquin-Gobeil, M., Wasserman, J., Weaver, J., Mimeault. et $\mathrm{Al}(2015)$. Clinical and pathological features of intraductal papillary neoplasm of the biliary tract and gallbladder. HPB, 17(9), 811-818. Doi:10. 1111/hpb.12460

[19] Sato, R., Ando, T., Tateno, H. et al. Intracystic papillary neoplasm with an associated mucinous adenocarcinoma arising in RokitanskyAschoff sinus of the gallbladder.surg case rep 2, 62 (2016).

[20] Farshad Moradi, MD PhD and Andrei lagaru, MD. The Role of Positron Emission Tomography in Pancreatic Cancer and Gallbladder Cancer. Seminars in Nuclear Medicine. https://doi.org/10.1053/j.semnuclmed.2020.04.002

[21] Adsay V, Jang KT, Roa JC, Dursun N, Ohike N, Bagci $P$, et al. Intracholecystic papillary-tubular 
neoplasms (ICPN) of the gallbladder (neoplastic polyps, adenomas, and papillary neoplasms that are $\geq 1.0 \mathrm{~cm}$ ): clinicopathologic and immunohistochemical analysis of 123 cases. Am J Surg Pathol. 2012; 36(9):1279-30

[22] neoplasms share pathological features with intraductal papillary neoplasm of the bile duct. Oncotarget. 2017;8(19):31532-9.

[23] Albores-Saavedra J, Adsay NV, Crawford JM, Klimstra DS, Kloppel G, Sripa B, Tsui WMS, Paradis V. Carcinoma of the gallbladder and extrahepatic ducts. In: Bosman FT, Carneiro F, Hruban RH, Theise ND, editors. WHO classification of tumours of the digestive system. 4th ed. Lyon: International Agency for Research on Cancer; 2010. p. 266-73.

[24] Ohtsuka M, Shimizu H, Kato A, Yoshitomi $H$, Furukawa K, Tsuyuguchi T, et al. Intraductal papillary neoplasms of the bile duct. Int $\mathrm{J}$ Hepatol. 2014; 2014:459091.

[25] Natov NS, Horton LC, Hegde SR. Successful endoscopic treatment of an intraductal papillary neoplasm of the bile duct. World J Gastrointest Endosc. 2017;9(5):238-42.

[26] Bennett S, Marginean EC, Paquin-Gobeil M, Wasserman J, Weaver J, Mimeault R, et al. Clinical and pathological features of intraductal papillary neoplasm of the biliary tract and gallbladder. HPB (Oxford). 2015;17(9):811-8.

[27] Mizobuchi, N., Munechika, J., Takeyama, N., Ohgiya, Y., Ohike, N., Abe, R., Gokan, T. (2018). Three cases of intracystic papillary neoplasm of gallbladder. Abdominal Radiology, 43(7), 1535-1539. doi:10.1007/s00261-0181595-z

[28] Sakamoto, K., Takai, A., Ueno, Y., Inoue, H., Ogawa, K., \& Takada, Y. (2019). Scoring System to Predict pt2 in Gallbladder Cancer Based on Carcinoembryonic Antigen and Tumor Diameter. Scandinavian Journal of Surgery, 145749691986601.doi:10.1177/145749691986 6016

[29] Bailey, A., \& Shah, S. A. (2019). Screening high risk populations for cancer: Hepatobiliary. Journal of Surgical Oncology. Doi:10.1002/jso.2533

[30] Halder A, Swain JR, Mohanty D, Majumder R. Gallbladder Carcinoma: Epidemiology, Risk Factors and Modes of Presentation in Eastern Part of India. Ann Clin Case Rep. 2020; 5: 1818. ISSN: 2474-1655

[31] Asmar, K., El Amine, M. A., Bejjani, A., Makki, M., Tamim, H., \& Abi-Ghanem, A. S. (2020). Factors influencing incidental 18F-FDG uptake in the gallbladder in a large cohort of patients: $A$ retrospective study. Clinical Imaging, 61, 4348.doi:10.1016/j.clinimag.2020.01.003
[32] Akita, M., Fujikura, K., Ajiki, T., Fukumoto, T., Otani, K., Hirose, T., Zen, Y. (2019). Intracholecystic Papillary Neoplasms Are Distinct From Papillary Gallbladder Cancers. The American Journal of Surgical Pathology, 43(6), 783791.doi:10.1097/pas.0000000000001237

[33] Epub, Ann \& Topal, Uğur \& Saritaş, Ahmet \& Ülkü, Abdullah \& Akçam, Atılgan \& Erdogan, Kivilcim \& Aydın, İshak. (2020). Intracholecystic Papillary-Tubular Neoplasms (ICPN) of the Gallbladder Intracholecystic Papillary-Tubular Neoplasms (ICPN) of the Gallbladder. Annali italiani di chirurgia. 9.

[34] R.A. Agha, M.R. Borrelli, R. Farwana, K. Koshy, A.J. Fowler, D.P. Orgill, et al.The SCARE 2018 statement: Updating consensus Surgical CAse REport (SCARE) guidelines. Int. J. Surg., 34 (2016 Oct), pp. 180-186 